\title{
STUDY COMPARATIVE OF ANTENNA FOR MICROWAVE IMAGING APPLICATIONS
}

\author{
Rachmat Agus Kurdyanto ${ }^{1}$, Nurhayati Nurhayati ${ }^{2}$, Puput Wanarti Rusimamto ${ }^{3}$,Farid Baskoro ${ }^{4}$ \\ Department of Electrical Engineering, Faculty of Engineering, Universitas Negeri Surabaya \\ Email: ${ }^{1}$ rachmatkurdyanto@mhs.unesa.ac.id \\ Email: ${ }^{2}$ nurhayati@unesa.ac.id \\ Email: ${ }^{3}$ puputwanarti@unesa.ac.id \\ Email: ${ }^{4}$ faridbaskoro@unesa.ac.id
}

\begin{abstract}
Microwaves can be applied for telecommunications, radar, and microwave imaging. This wave has been widely used in everyday life, such as in the industrial world in the fields of robotics, microwave vision, imaging buried objects, vehicular guidance, biomedical imaging, remote sensing, weather radar, target tracking, and other applications. Microwave imaging is a technology that uses electromagnetic waves at frequencies from Megahertz to Gigahertz. Utilization of microwave imaging in addition to information technology and telecommunications, this wave application can be used to process an image because of its ability to penetrate dielectric materials. The purpose of writing this article is to determine microwave imaging applications, the working principle of antennas used for microwave imaging applications, and antenna specifications used for microwave imaging applications. Microwave imaging research has been carried out using several different types of antennas such as Vivaldi and monopole antennas. Where the signal that is transmitted and will be exposed to the object will send a different return signal so that an image of an object will be obtained which will be processed on the computer. The working frequency of the antenna for microwave imaging applications is in a wide frequency range (UWB antenna). The antennas that are applied include the Vivaldi antenna which works at a frequency of 1-11 GHz and a monopole antenna that works at a frequency $1,25-2,4 \mathrm{GHz}$ for biomedical imaging applications, while for radar applications in the construction field it can use a frequency of $0,5-40 \mathrm{GHz}$.
\end{abstract}

Keywords: microwave imaging, Vivaldi antenna, ultra-wideband

\section{INTRODUCTION}

Microwave imaging is an imaging technology that uses electromagnetic wave frequencies several hundred Megahertz to Gigahertz [2], imaging buried objects, vehicular guidance, biomedical imaging [3], remote sensing, weather radar, target tracking, and other applications apart from information and communication technology. microwave applications can be used to process images [4] because of the ability of microwave waves to penetrate dielectric materials. Imaging applications in the industrial and medical fields can be applied to detect cracks in building structures, metal detectors [5] [6], brain damage detection [7], skin cancer [8], breast cancer [9] [10], lung detection. [11] [12], heart and others. Microwave imaging applications in the medical field can use CT scans, MRI or X-Ray. However, the use of CT scans and MRI is only available in certain hospitals, and they are not portable and their procurement requires a very large cost.
Microwaves can be applied to various applications because these waves have certain characteristics of a coherent electric field distribution on the target to be detected [13]. Besides, microwaves can be used in various applications because of their ability to penetrate dielectric materials. The scattered or reflected signal from these materials is measured and processed to obtain an image of the target so that it can show the characteristics of the target [14]. The advantages of microwave over other methods are low cost, fast, non-invasive, and non-ionizing which leads to a safe and convenient testing procedure [15]. The detection process using microwaves can be done using transmitters or receivers and antennas that work at microwave frequencies and can operate in a frequency range with a wide bandwidth that has a directed radiation pattern. The data received from the microwave transceiver will be subjected to signal conditioning and data acquisition processes. The 
collected data is processed so that an image is formed using a certain algorithm [16].

An antenna as the front end of a wireless device system connected to a transmitter or receiver as an electric signal converter into an electromagnetic plays an important role in the process of sending data. Microwave imaging application is the process of obtaining an image of an object using microwaves operating from a frequency of 1 to $30 \mathrm{GHz}$ due to differences in the dielectric constant difference of the detected object [17]. The purpose of this study was to determine the working principle of the antenna used for microwave imaging applications, to determine the types of antennas used and the performance of the antenna produced for several microwave imaging applications.

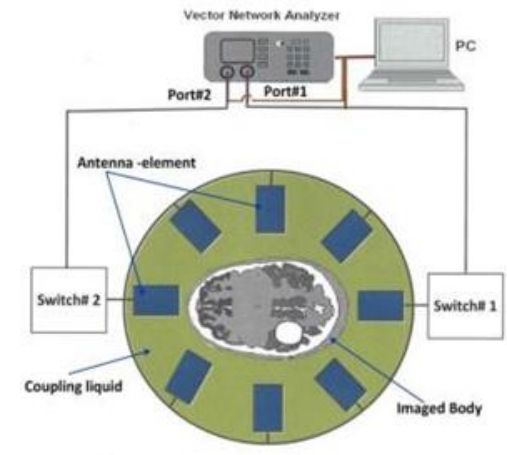

(a)

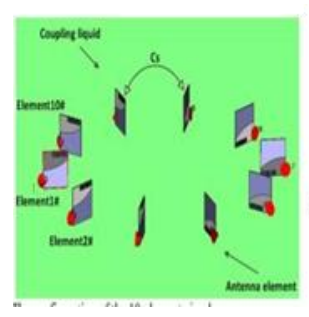

(b)

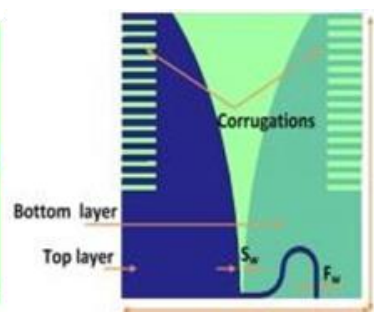

(c)
Figure 1. (a) Brain imaging block diagram for stroke detection, (b) 10 element circular array configuration, (c) antenna configuration [17].

\section{METHODS}

Microwave imaging research has been carried out using several different antenna types. Microwave imaging application to detect brain tumors has been carried out by [17] using Antipodal Vivaldi Antenna (AVA) where the transmitted signal and the target/object will send a different scattered signal back so that an image of the object will be processed on the computer as seen in Figure 1.

The use of monopole antennas for microwave imaging head applications is also carried out using monopole antennas that can operate at wideband frequencies using the FR4 substrate with a permitifity 4.5 operating at a frequency of $1.25-2.4 \mathrm{GHz}$ [18] can be seen in Figure 2.

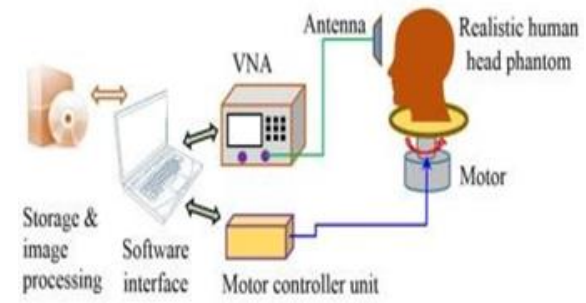

(a)

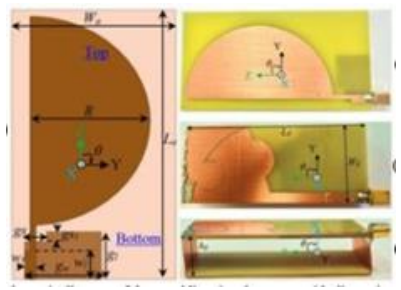

(b)

Figure 2. (a) Head imaging experiment and (b) omnidirectional monopole antenna [18]

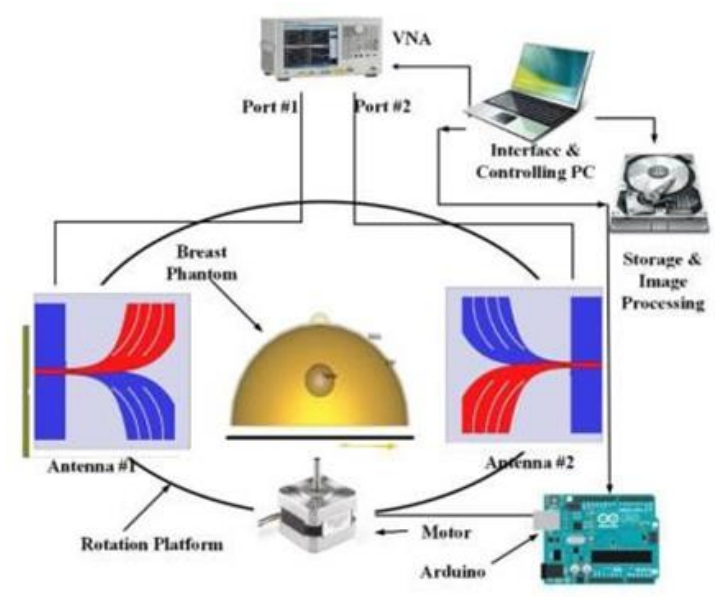

Figure 3. Block Diagram of Breast Tumor Imaging [19]

Figure 3 shows the application of a vivaldi antenna with a size of $0.401 \lambda \times 0.401 \lambda \times 0.016 \lambda$ as a breast imaging sensor that operates at an ultra-wideband frequency of 3.01-11 GHz that has been studied [19] 


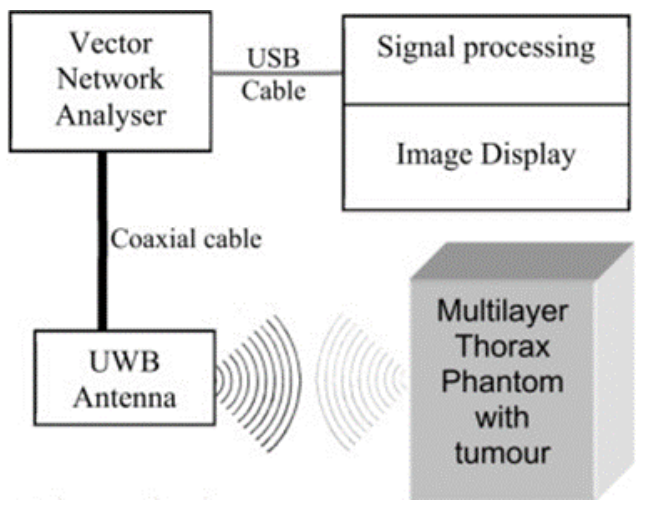

(a)

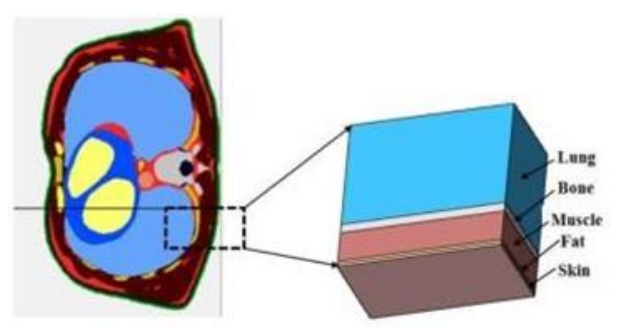

(b)

Figure 4. (a) Microwave imaging setup of the lung and (b) Multilayer thorax modeling [20]

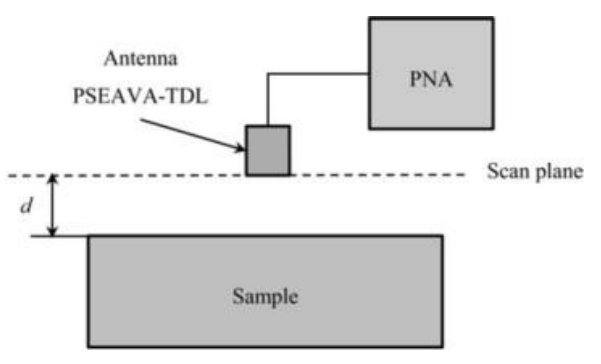

(a)

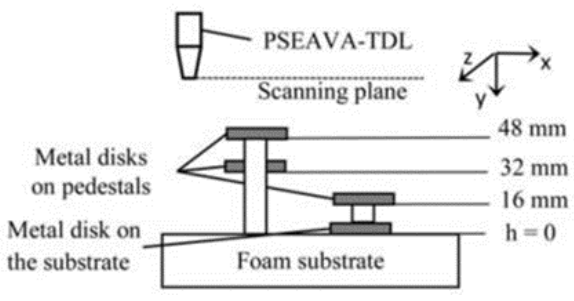

(b)

Figure 5. Setup of measurements for imaging material construction [21].
Lung imaging simulations were carried out by measuring the scattering response of the phantom that consisting of lung tissue (70mm), $6 \mathrm{~mm}$ bone partition,

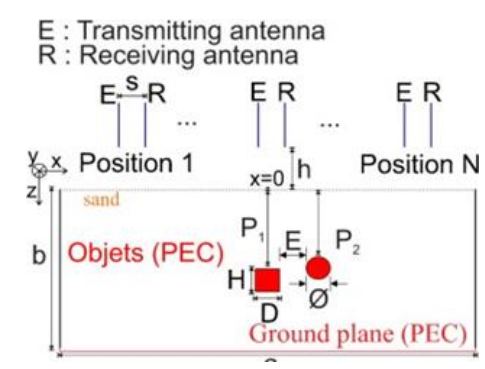

(a)

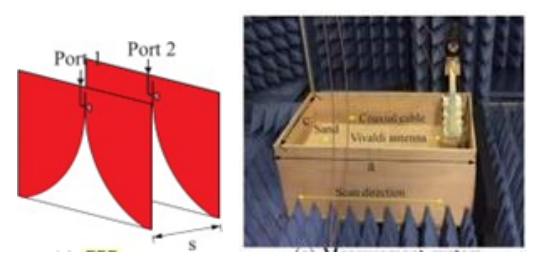

(b)

(c)

Figure 6. (a) GPR measurement scenario, (b) antenna GPR and (c) measurement system [22].

$20 \mathrm{~mm}$ muscle partition, $2 \mathrm{~mm}$ fat partition, and $2 \mathrm{~mm}$ skin partition using the ultrawideband antenna shown in Figure 4. For microwave imaging, it uses frequency 3 to $5 \mathrm{GHz}$, with tissue in simulating liquid. In the experiment, the inhallation and exhallaion is examined to get scatering parameter image. The data from experiment result is processed by image algorithm and reconstruction.

Microwave imaging can also be applied for the detection of metal cracks, building cracks, and objects in the ground as a Ground-penetrating Radar (GPR) as seen in Figure 5.Antiipodal Vivaldi antenna that works at a frequency of 3.4-4 GHz with a size of $40 \times 90 \times$ $0.508 \mathrm{~mm} 3$ and adding a slit and a lens to increase the antenna gain up to $16 \mathrm{~dB}$ has been investigated for material construction applications [21].

Antenna research for bi-static GPR applications for underground targets using two identical pieces working at a frequency of 0.5 to $3 \mathrm{GHz}$ has been carried out [22] which can be seen in Figure 6. The radargram from target detection is examined with and without burried object in the sandbox.

The use of UWB antennas to detect the presence of objects, in this case, human respiration behind a wall, has been carried out using the Vivaldi antenna, which can be seen in Figure 7. The antenna used works in the S-band frequency, namely $2-4 \mathrm{GHz}$ using a transmitter antenna and 5 receiving antennas [23]. The signals from target are complex and it needs filter process to remove 
the unwanted signal. Back Projection algorithm is used in the image processing to get the visualization of the object behind the concreate wall.

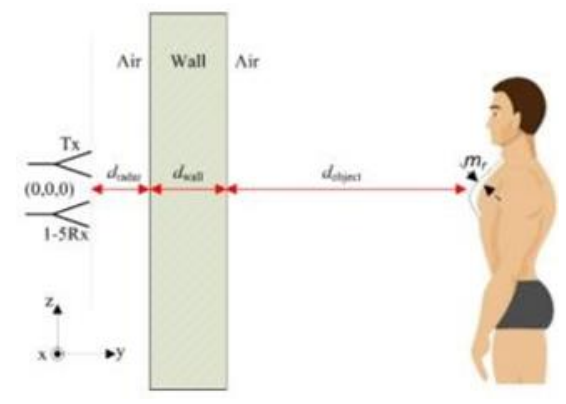

(a)

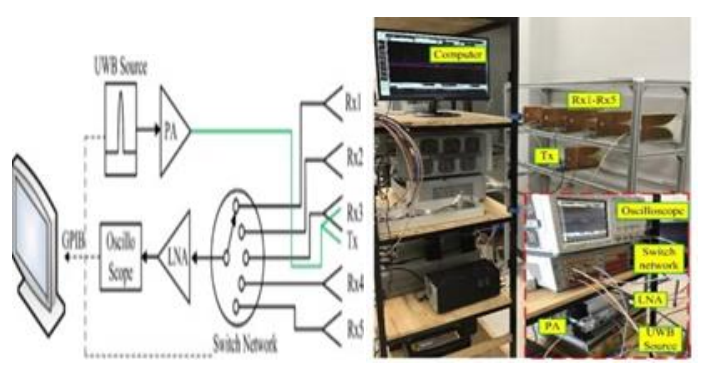

(b)

(c)

Figure 7. (a) Measurement of radar UWB against human objects, (b) block diagrams of $1 \mathrm{Tx}$ and $5 \mathrm{Rx}$, and (c) Experimental antenna array setup on radar prototype [23]

\section{RESULTS AND DISCUSSION}

The use of antennas for microwave imaging applications has been applied to several applications in the fields of biomedical imaging, GPR, wall through radar, and others. The electromagnetic wave signal emitted by the signal source will be exposed to the target object, which will then serve the reflected signal from the object part to be received back by the receiving antenna and will be processed on the computer and produce a visualization of the object. The antenna as the front end of sending and receiving data plays a very important role. Antennas that are applied for microwave imaging generally work on a wide bandwidth, according to the Federal Communication Commission (FCC) that technology is said to be ultra wideband if it has a bandwidth of more than $500 \mathrm{MHz}$ or more than 20\% where:

$$
b w=2 \frac{f_{u}-f_{l}}{f_{u}+f_{l}} \geq 0.2, \quad b w=f_{u}-f_{l} \geq 500 M H z
$$

$f_{u}$ is the upper frequency and $f_{l}$ is the lower frequency. The following are some of the resulting images from the antenna and target testing which can be seen from Figure 8 to Figure 13.

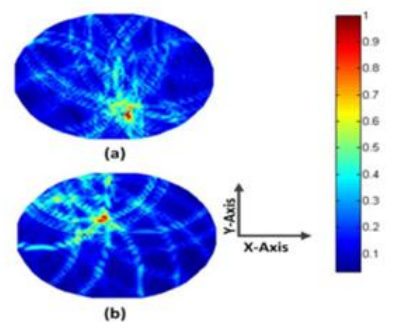

Figure 8 Target imaging at coordinates (a) 16, -54 and (b) $-16,19$ [17]

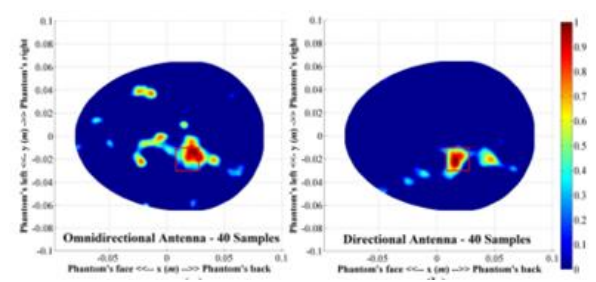

Figure 9. Image reconstruction using an omnidirectional antenna and directional antenna using

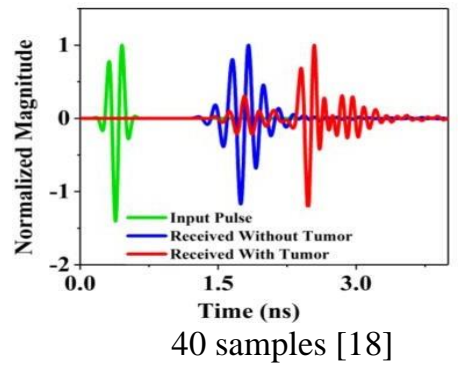

Figure 10. Normalized amplitude with and without tumor [19]

Figure 8 and Figure 9 are target imaging results of the target detection. The scattering parameter result from the measurement result is constructed by image processing. In[17] the imaging algorithm uses delay and sum as the confocal algorithm. They use $16 \mathrm{~cm} 15 \mathrm{~cm}$ x $5 \mathrm{~cm}$ of head tissue with an elliptical radius of $8.5 \mathrm{~cm}$ and $7.5 \mathrm{~cm}$. The dielectric permittivity of the shell is 5 , with conductivity 0.05 , and the permittivity inside the shell 42 and conductivity 0.99 by CST simulation. $\operatorname{In}[18], 1.25-2.4 \mathrm{GHz}$ antenna with the omnidirectional and directional antenna are compared. The directional antenna shows stronger near field imaging than the omnidirectional antenna. Figure 10 shows the magnitude of the scattered signal with and without tumor. The graph performs the presence of a delay signal for the tumor phantom. Figures 11-13 show the target detection with a different target, algorithm, and resolution of image processing. It shows the success of target detection with UWB antenna. 


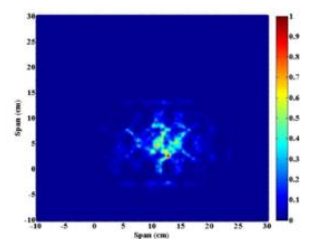

Figure 11. Image reconstruction of the inhalation model [20]
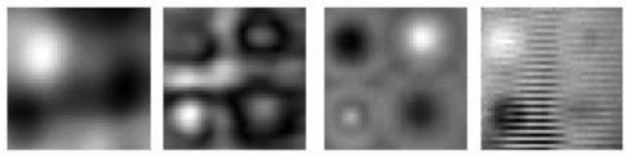

Figure 12. 2D image without image processing at frequencies $3.4 \mathrm{GHz}, 9.6 \mathrm{GHz}, 25.7 \mathrm{GHz}$, and $40 \mathrm{GHz}$ [21]

(a)

(b)

Table 1. Comparison of antenna performance for microwave imaging applications

\begin{tabular}{|c|c|c|c|c|c|}
\hline ref & antenna shape & $\begin{array}{c}\text { Working } \\
\text { Frequency } \\
(\mathrm{GHz})\end{array}$ & $\begin{array}{c}\text { Bandwidth } \\
\text { (GHz) }\end{array}$ & Gain (dBi) & Application \\
\hline [17] & & $1-4$ & 4 & NA & $\begin{array}{c}\text { Human brain } \\
\text { detector }\end{array}$ \\
\hline [18] & & $1,25-2,4$ & 2,4 & 3,5 & $\begin{array}{c}\text { Human head } \\
\text { detector }\end{array}$ \\
\hline [19] & & 2,97 & $2,97-15$ & 10 & $\begin{array}{c}\text { Breast tumor } \\
\text { detector }\end{array}$ \\
\hline [21] & & $3,4-40$ & 40 & 16 & $\begin{array}{c}\text { Construction } \\
\text { material } \\
\text { detector }\end{array}$ \\
\hline [22] & & $0,5-3,5$ & $\overline{3,5}$ & 2,35 & $\begin{array}{l}\text { Search for } \\
\text { objects in } \\
\text { the ground }\end{array}$ \\
\hline [23] & & $2-4$ & 5,2 & 10 & $\begin{array}{c}\text { Human } \\
\text { detection } \\
\text { through } \\
\text { Wall }\end{array}$ \\
\hline
\end{tabular}


Antenna as the front end of a data transmission system can function as a sensor, namely as an interface that converts electrical signals into electromagnetic waves. Microwaves can be applied in many applications including imaging applications. Based on research [17] the use of the Vivaldi antenna with a corrugated structure can work with a wide frequency of $1-4 \mathrm{GHz}$ and arranged in a circular array but has a low mutual coupling value, which is below $-20 \mathrm{~dB}$. The antenna used has dimensions (24 mm x $24 \mathrm{~mm}$ ) using a substrate RT 6010 with a thickness of 0.635 and a permittivity of 10.2. The antenna is tested on fluids that have a dielectric value compatible with brain tissue. The process of detecting the brain is carried out by using the delay and sum algorithm in reference [24]. The circular array used includes 10 elements of the band antenna.

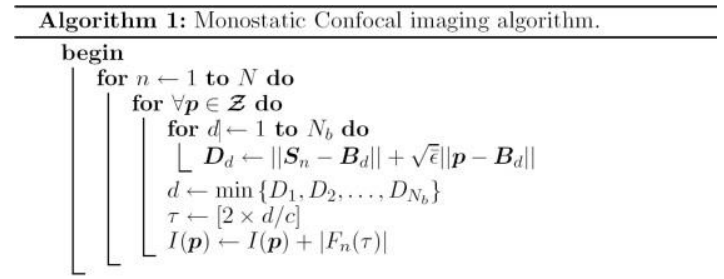

$\overline{\text { Gambar 14. Algoritma imaging monostatic confocal. }}$. [24]

Research on head imaging with microwaves carried out using directional and omnidirectional antennas covering a frequency of $1.25-2.4 \mathrm{GHz}$ and a gain of 3.5 $\mathrm{dB}$ has been discussed in [25]. These studies show that directional antennas can provide better impulse performance with lower distortion than omnidirectional antennas. Microwaves in the study [19] play an important role in detecting breast tumors by testing them on artificial phantoms. Microwave applications are also used for imaging construction materials [21].

Microwaves and high-quality millimeter waves are used to examine construction materials by using antennas that operate at a very wide frequency or ultrawideband frequency to provide high imaging resolution and depth of detection for more detail. This layered structure imaging can detect plasterboard with air gaps in the form of distances of air cavities and other parts. In another study, microwaves also play a role in finding an object using ground-penetrating radar (GPR) [22] using a Vivaldi antenna operating at 0.5 to $3.5 \mathrm{GHz}$. In this study, GPR scan data were obtained through measurement and simulation in the object buried. Besides, microwave applications are also developed in human detection systems behind walls [23]. This research proposes an S-band array antenna radar scheme through the wall where the antenna used is 1 transmitting antenna (Tx) and 5 receiving antennae $(\mathrm{Rx})$ of the
Vivaldi type with a gain of $10 \mathrm{dBi}$ where the object moves at a narrow-angle. The 2-4 GHz S-band frequency allows it to penetrate non-metallic solid objects and detect human respiration behind walls.

From Table 1, it can be seen that the antennas used for microwave imaging applications are mostly Vivaldi antennas that work at a wide frequency. Research using a vivaldi antipodal antenna with a corrugated structure and adding a lens to the substrate will increase the gain up to $16 \mathrm{~dB}$.

\section{CONCLUSION}

Comparative antenna studies for microwave imaging applications have been carried out. Microwave waves can be applied to biomedical imaging including detection of the brain, breast tumors, lung cancer, and others, and can also be used for radar applications including ground-penetrating radar (GPR), detection of metal cracks, and objects behind walls. Medical imaging uses an antenna that works in a wide bandwidth / wideband antenna with a bandwidth of more than $500 \mathrm{MHz}$. The process of detection by measurement is carried out by connecting the antenna with the vector network analyzer and the signal is transmitted to the phantom and object and with the presence of a signal that is reflected from the object in the form of a scattering signal, image processing will be carried out so that the characteristics of the object detected are obtained. Antennas used for microwave imaging applications can be in the form of omnidirectional antennas or directional antennas and can be Vivaldi antennas with a gain above $2 \mathrm{dBi}$ in the form of a single element or an array antenna. The structure detector can use a frequency of up to 40 $\mathrm{GHz}$, GPR uses a frequency of $3.5 \mathrm{GHz}$, and the object detector behind a wall can use a frequency of $5.2 \mathrm{GHz}$.

\section{REFERENSI}

[1] C. Ten, "Applications of," in APPLICATIONS OF MICROWAVE IMAGING, John Wiley \& Sons, Inc, 2010.

[2] S. Patwa, S. Yadav, and M. Saqib, "Importance of Microwave Antenna in," pp. 433-437, 2018, doi: 10.15662/IJAREEIE.2018.0702008.

[3] M. Bavusi, F. Soldovieri, S. Piscitelli, A. Loperte, F. Vallianatos, and P. Soupios, "Ground-penetrating radar and microwave tomography to evaluate the crack and joint geometry in historical buildings : some examples from Chania , Crete, Greece," pp. 377-387, 2010, DOI: 10.3997/18730604.2010039.

[4] S. Klein, M. Staring, K. Murphy, M. A. Viergever, and J. P. W. Pluim, "Elastix: A Toolbox for Intensity-Based Medical Image Registration," vol. 29, no. 1, pp. 196-205, 2010. 
[5] A. Mohan and S. Poobal, "Crack detection using image processing : A critical review and analysis," Alexandria Eng. J., 2017, DOI: 10.1016/j.aej.2017.01.020.

[6] R. Zoughi and S. Kharkovsky, "Microwave and millimeter wave sensors for crack detection R.," pp. 695-713, 2008, DOI: 10.1111/j.1460-2695.2008.01255.x.

[7] M. T. Student, C. Deptt, and C. Deptt, "Calculation of Specific Absorption Rate ( SAR ) of Patch antenna on Human Brain and Design of Low SAR value Microstrip Patch Antenna," vol. 5, no. 4, pp. 116-121, 2018.

[8] K. Chand, P. Mehta, D. G. Beetner, R. Zoughi, and W. V Stoecker, "Microwave Reflectometry as a Novel Diagnostic Method for Detection of Skin Cancers," no. May, pp. 17-19, 2005.

[9] H. Song, H. Sato, X. Xiao, and T. Kikkawa, "A Portable Breast Cancer Imaging System with Cross-shaped Dome Antenna Array," 2017 11th Eur. Conf. Antennas Propag., pp. 3474-3475, 2017, DOI:

10.23919/EuCAP.2017.7928284

[10] M. T. Islam, M. Z. Mahmud, N. Misran, J. I. Takada, and M. Cho, "Microwave Breast Phantom Measurement System with Compact Side Slotted Directional Antenna," IEEE Access, vol. 5, pp. 5321-5330, 2017, DOI: 10.1109/ACCESS.2017.2690671.

[11] S. N. Muhammad, M. M. Isa, and F. Jamlos, "Review article of microwave imaging techniques and dielectric properties for lung tumor detection Review Article of Microwave Imaging Techniques and Dielectric Properties for Lung Tumor Detection," vol. 20012, no. January 2020.

[12] O. J. Babarinde and M. F. Jamlos, "UWB Microwave Imaging for Lung Tumor Detection in a Thorax Model," 2014 IEEE Symp. Wirel. Technol. Appl., pp. 130-133, 2014, doi: 10.1109/ISWTA.2014.6981172.

[13] M. Tayeb and A. Ghasr, Mine Real-time and portable microwave imaging system. 2009.

[14] B. J. Mohammed, A. M. Abbosh, S. Member, S. Mustafa, and D. Ireland, "Microwave System for Head Imaging," vol. 63, no. 1, pp. 117-123, 2014

[15] M. Saiful, R. Bashri, T. Arslan, and W. Zhou, "Flexible Antenna Array for Wearable Head Imaging System," 2017 11th Eur. Conf. Antennas Propag., pp. 172- 176, 2017, DOI: 10.23919/EuCAP.2017.7928757.
[16] A. T. Mobashsher, A. Mahmoud, and A. M. Abbosh, "Portable Wideband Microwave Imaging System for Intracranial Hemorrhage Detection Using Improved Backprojection Algorithm with Model of Effective Head Permittivity," Nat. Publ. Gr., no. March 2015, pp. 1-16, 2016, DOI: $10.1038 /$ srep20459.

[17] B. J. Mohammed, A. M. Abbosh, and D. Ireland, "Circular Antenna Array for Brain Imaging Systems," Proc. 2012 IEEE Int. Symp. Antennas Propag., pp. 1-2, 2012, DOI: 10.1109/APS.2012.6348799.

[18] A. T. Mobashsher, S. Member, A. M. Abbosh, and S. Member, "Performance of Directional and Omnidirectional Antennas in Wideband Head Imaging," vol. 1225, no. c, pp. 1-4, 2016, DOI: 10.1109/LAWP.2016.2519527.

[19] M.T. Islam, Md Samsuzzaman, Md. T. Islam, S. Kibria, M.J. Singh, I, "A Homogeneous Breast Phantom Measurement System with an Improved Modified Microwave Imaging Antenna Sensor,”, Sensors, 2018, DOI: 10.3390/s18092962.

[20] O. J. Babarinde, M. F. Jamlos, P. J. Soh, D.M. M. P. Schreurs, and A. Beyer, "Microwave Imaging Technique for Lung Tumour Detection," 2016 Ger. Microw. Conf., pp. 100-103, 2016, DOI: 10.1109/GEMIC.2016.7461566.

[21] M. Moosazadeh, S. Kharkovsky, and J. T. Case, "Microwave and millimeter-wave antipodal Vivaldi antenna with the trapezoid-shaped dielectric lens for imaging of construction materials," IET Microwaves, Antennas Propag., vol. 10, no. 3, pp. 301-309, 2016, DOI: 10.1049/iet-map.2015.0374.

[22] X. Liu, M. Serhir, A. Kameni, M. Lambert, and L. Pichon, "Buried targets detection from synthetic and measured B-scan ground-penetrating radar data," 2017 11th Eur. Conf. Antennas Propagation, EUCAP 2017, pp. 1726-1730, 2017, DOI: $10.23919 / \mathrm{EuCAP} .2017 .7928686$.

[23] A. Rittiplang and P. Phasukkit, "1-Tx/5-Rx Through-Wall UWB Switched-Antenna- Array Radar for Detecting Stationary Humans," Sensors, pp. 2-17, 2020.

[24] S. Y. Semenov and D. R. Corfield, "Microwave Tomography for Brain Imaging: Feasibility Assessment for Stroke Detection," Int. J. Antennas Propag., vol. 2008, pp. $\quad 1-8, \quad 2008, \quad$ DOI: $10.1155 / 2008 / 254830$.

[25] A. T. Mobashsher and A. M.Abbosh, "Performance of directional and omnidirectional antennas in wideband head imaging," IEEE Antennas Wirel. Propag. Lett., vol. 15, no. c, pp. 1618-1621, 2016, DOI: 10.1109/LAWP.2016.2519527. 